\title{
Evaluation of Ganoderma lucidum strains for the production of bioactive components and their potential use as antimicrobial agents
}

\author{
Harsimran Kaur, Shivani Sharma*, P.K. Khanna and Shammi Kapoor \\ Department of Microbiology, Punjab Agricultural University, Ludhiana -141004 (Punjab), INDIA \\ *Corresponding author. E-mail: shivaniattri@gmail.com \\ Received: November 8, 2014; Revised received: February 6, 2015; Accepted: April 20, 2015
}

Abstract: In the present study, mycelial biomass of Ganoderma lucidum strains was produced in mushroom complete media under optimized culture conditions of temperature, $\mathrm{pH}$, agitation and the fruiting bodies were raised on wheat straw supplemented with 5 per cent rice bran. Maximum biomass $\left(16.39 \mathrm{mg} \mathrm{ml}^{-1}\right)$ was recorded in strain GL-3 and minimum (10.99 mg ml${ }^{-1}$ ) was observed in strain GL-1 after 28 days of incubation period. Maximum biological efficiency of 13.1 per cent was obtained in 57 days in GL-2 strain. Moreover, weight of fruiting bodies was highest $\left(91 \mathrm{~g} \mathrm{bag}^{-1}\right)$ in 5 per cent wheat bran supplemented bags in strain GL-2. Polysaccharides were extracted, characterized and analysed. The maximum yield of polysaccharides was obtained from fruiting bodies (30.06- 63.70\%), followed by mycelial biomass $(7.61-21.32 \%)$ and culture filtrates $(0.86-2.86 \%)$. Non-reducing sugars were the main fraction of sugars which constituted 69.82- 70.39 per cent in fruiting body extracted polysaccharides, 62.08- 83.39 per cent in biomass and 59.75- 77.54 per cent in crude extracts. The extracts from fruiting bodies and biomass of G. lucidum strains also exhibited antibacterial effect against some pathogenic bacteria, Staphylococcus sp. and Enterobacter $\mathrm{sp}$. The present study clearly indicated that variations existed among $\mathrm{G}$. lucidum strains with respect to the production of bioactive molecules, yield and antimicrobial activity. Bioactive components from G. lucidum strains are promising antimicrobial agents that can be harnessed as potent antimicrobial toxicant.

Keywords: Antimicrobial activity, Biological efficiency, Ganoderma lucidum, Polysaccharides

\section{INTRODUCTION}

Ganoderma lucidum is a medicinal fungus in Polyporaceae. The fungus is saprobic in nature, growing alone or in groups on decaying hardwood logs. It is known as 'lingzhi' and was first indexed in Shen Nong's Materia Medica (206 BC-8 AD) as a longevity-promoting and tonic herb of the non-toxic superior class (Zhu et al., 2007). It has been used in traditional Chinese medicine for more than 2000 years to prevent and treat diseases including hepatitis, chronic bronchitis, gastritis, tumor growth and immunological disorders (Lin and Zhang, 2004). The chemical components of G. lucidum extracted from the fruiting body, mycelium, or spores includes polysaccharides, flavonoids, alkaloids, amino acids, steroids, oligosaccharides, proteins and mannitol (Zjawiony, 2004). Among these components, G. lucidum polysaccharides and triterpenes have been identified as the major bioactive components, showing multiple pharmacological effects, such as immunomodulation, anti-oxidation, hepatoprotection, anti-proliferation, and anti-angiogenesis ( $\mathrm{Xu}$ et al., 2011). Each fraction of polysaccharides and triterpenes has more than 100 molecules that have been isolated, most of these are potent immunomodulators and/or antioxidants and are also chemopreventive and tumoricidal (Gao et al., 2002 and 2004). The lingzhi isolated polysaccharides are macromolecules, having a molecular weight range from $4 \times 10^{5}$ to $1 \times 10^{6}$ Dalton in the primary structure. Most of these polysaccharides are extractable with hot water, salt solutions, alkali solutions, and dimethyl sulfoxide solution. The purified molecules are less soluble in water and become more soluble in alkali (Gao et al., 2004). The extracts of G. lucidum have also been reported to be active against Bacillus subtilis and Pseudomonas syringes which are plant pathogen (Ofodile et al., 2005). Traditionally, bioactive components have been extracted from fruiting bodies. However, mycelial biomass production forms a promising future platform for fully standardized production of safe mushroom based dietary supplements containing these bioactive components. The present investigation elucidates interesting chemical compounds extracted, purified and identified from fruiting body, mycelial biomass and culture filtrate of $G$. lucidum strains and their evaluation against some pathogenic isolates of bacteria.

\section{MATERIALS AND METHODS}

Mycelial biomass and fruiting bodies: The mycelial biomass of G. lucidum strains (GL-1, GL-2 and GL-3) was raised in the mushroom complete medium (Glucose-20g, Peptone- 2.0g, Yeast extract- 2.0, $\left.\mathrm{KH}_{2} \mathrm{PO}_{4}-0.5 \mathrm{~g}, \mathrm{~K}_{2} \mathrm{HPO}_{4}-1.0 \mathrm{~g}, \mathrm{MgSO}_{4} .7 \mathrm{H}_{2} \mathrm{O}-0.5 \mathrm{~g}\right)$ under optimized conditions of temperature $\left(30^{\circ} \mathrm{C}\right), \mathrm{pH}$ 
(5.0) and agitation (100 rpm) after 28 days. Fruiting bodies were also raised on sterilized wheat straw supplemented rice bran $(5 \% \mathrm{w} / \mathrm{w})$ substrate. Fruit bodies were harvested after maturity. Biological efficiency (B.E.) was calculated using the following formula (Chang and Miles, 2004).

Extraction and analysis of polysaccharide: The polysaccharides were extracted from the mycelial biomass, culture filtrate of three G. lucidum strains (GL-1, GL-2 and GL-3) and fruiting bodies of GL-1 and GL-2 strains using method by Yap and Ng, (2001). The mycelial biomass raised in MCM for all the three strains was filtered through Whatmann no.1 filter paper and washed with distilled water. About $15 \mathrm{~g}$ of the mycelium was homogenised in a tissue homogeniser, transferred to a $500 \mathrm{ml}$ round bottomed flask and 100 $\mathrm{ml}$ of distilled water was added to it. The samples in the round bottomed flasks fitted with condensers, were refluxed on a hot plate at $100^{\circ} \mathrm{C}$ for $10 \mathrm{hrs}$. The refluxed samples were cooled and filtered through Whatmann filter paper no.1.The filtrates obtained were used for the extraction of polysaccharides, while the residues left were discarded. The filtrates were concentrated to about $1 / 10^{\text {th }}$ of the original volume by evaporating water from them with the use of distillation condensers and were cooled.

To the concentrated extracts, the equal amount of pre-chilled ethanol $\left(4^{\circ} \mathrm{C}\right)$ was added after cooling to room temperature and the samples were kept at $-20^{\circ} \mathrm{C}$ for $2 \mathrm{hrs}$ in order to get complete precipitation of polysaccharides. After precipitation, the samples were centrifuged in a cooling centrifuge (Remi) at $4^{\circ} \mathrm{C}$ for $20 \mathrm{~min}$ at 6000 $\mathrm{rpm}$. The residue so obtained was the first fraction of polysaccharides which was collected in a pre-weighed glass vial and stored at room temperature. The supernatant left after centrifugation was used for the extraction of second fraction of polysaccharides. Again equal volume of ethanol was added to the supernatant, kept at $-20^{\circ} \mathrm{C}$ for overnight. Next day, the suspension was centrifuged at $4^{\circ} \mathrm{C}$ in a cooling centrifuge at $6000 \mathrm{rpm}$ for $20 \mathrm{~min}$. The residue obtained was collected as the second fraction of polysaccharides in glass vials and stored at room temperature while the supernatant left after centrifugation was discarded. The crude extracts left after filtration of mycelial biomass were as such concentrated without refluxing for $10 \mathrm{hrs}$ and precipitated repeatedly with chilled ethanol so as to separate the polysaccharides from them. Similar procedure was followed for the extraction of polysaccharides from the fruiting bodies of GL-1 and GL-2 strains of G. lucidum.

The percentage yield obtained in all the samples was then calculated by the following formula:

The polysaccharides were quantitatively analysed by estimating the amount of polysaccharides obtained after extraction process. The estimation was done for total sugars by Dubois et al. (1956) as well as reducing sugars by Miller (1959).

Antimicrobial activity: The antibacterial activity of various extracts of G. lucidum strains was determined against the bacterial cultures of Staphylococcus sp., Salmonella sp., Enterobacter sp., Pseudomonas sp., Klebsiella sp. and E. coli procured from Sawai Mansingh General Hospital and Medical College, Jaipur, India. The cultures were maintained in sterile nutrient agar slant at $4{ }^{\circ} \mathrm{C}$.

Preparation of mushroom extracts: Two types of extracts (Methanolic and aqueous extract) were used for the assessment of antimicrobial activity of the mushroom. The mycelium of all the three strains of $G$. lucidum was used for preparing two kinds of extracts. GL-3 strain produced no fruiting bodies hence methanolic and aqueous extracts were prepared for the fruiting bodies of GL-1 and GL-2 strains.

Methanolic extracts: The methanolic extracts of mycelium and fruit bodies were prepared using methanol as an extracting solvent according to the methodology of Kalsi (2002). $5 \mathrm{~g}$ of fresh mycelium of

$$
\text { B.E. }(\%)=\frac{\text { Fresh wt of mushrooms }}{\text { Dry wt of substrate }} \times 100
$$

each strain of G. lucidum were refluxed with $50 \mathrm{ml}$ of methanol at $40^{\circ} \mathrm{C}$ on water bath for $4 \mathrm{hrs}$. The contents were filtered through pre-sterilized Whatmann no.1 filter papers and cooled. The extracts obtained were left overnight at room temperature to evaporate the methanol and were collected in pre-sterilized screw capped glass vials. Similarly, $5 \mathrm{~g}$ of dried and powdered fruit body of GL-1 and GL-2 strains were used to prepare the methanolic extract in a similar manner and stored at $4^{\circ} \mathrm{C}$.

Aqueous extract: The hot water extracts were prepared using mycelium and fruit body. $5 \mathrm{~g}$ of fresh mycelium of all the three strains of G. lucidum were heated with $100 \mathrm{ml}$ of distilled water on a boiling water bath at $100^{\circ}$ $\mathrm{C}$ for $8 \mathrm{hrs}$. The contents were filtered through pre-sterilized Whatmann no.1 filter papers and cooled to room temperature. The extracts were collected in pre-sterilized screw capped vials and stored at $4^{\circ} \mathrm{C}$ in refrigerator until use. The aqueous extract of the fruit body of GL -1 and GL-2 strains were also prepared in a similar way using five $\mathrm{g}$ of dried, powdered sample and then stored.

Antimicrobial activity of methanolic and aqueous extracts was evaluated by the filter paper disc and spectrophotometeric method. Experiment was set up in three replications. Plates and liquid medium were incubated at $37^{\circ} \mathrm{C}$ for 24 to $48 \mathrm{hrs}$.

\section{RESULTS AND DISCUSSION}

Liquid culture studies for biomass production: Three strains of G. lucidum, GL-1, GL-2 and GL-3 were grown in mushroom complete medium adjusted at $\mathrm{pH} 6.0$ value. Results indicated the increase in biomass yields with increase in incubation up to 28 days. Maximum biomass yield production values were recorded in 
Table 1. Biomass production of G. lucidum strains.

\begin{tabular}{lcccc}
\hline Strain & \multicolumn{4}{c}{ Incubation period (Days) } \\
\cline { 2 - 5 } No. & \multicolumn{4}{c}{ Dry biomass (mg g $\mathbf{~}^{-1}$ ) } \\
\cline { 2 - 5 } & $\mathbf{7}$ & $\mathbf{1 4}$ & $\mathbf{2 1}$ & $\mathbf{2 8}$ \\
\hline GL-1 & 6.17 & 7.17 & 8.80 & 10.99 \\
GL-2 & 4.94 & 8.31 & 10.19 & 12.74 \\
GL-3 & 10.69 & 11.93 & 15.38 & 16.39 \\
CD at 5\% & 1.22 & 1.34 & 1.53 & 1.28 \\
\hline
\end{tabular}

Average of 5 replicates; Medium: Mushroom complete medium; Incubation temperature: $30 \pm 2^{\circ} \mathrm{C}$

strain GL-3 $\left(16.39 \mathrm{mg} \mathrm{ml}^{-1}\right)$, GL-2 $\left(12.74 \mathrm{mg} \mathrm{ml}^{-1}\right)$ and the least for GL-1 $\left(10.99 \mathrm{mg} \mathrm{ml}^{-1}\right)$ after 28 days of incubation period. Rate of biomass production was more from 14-21 days of incubation (Table 1). Varied biomass production values have been recorded by different workers depending upon the medium used, initial $\mathrm{pH}$, incubation period and type of cultivation system used. Kim et al. (2002) found that mushroom complete medium supported maximum biomass production in case of G. lucidum as compared to yeast malt extract (YM) and potato malt peptone (PMP). The dry cell weight after 15 days of incubation was $6.24 \mathrm{~g} 1$

${ }^{-1}$ for G. lucidum. In case of YM and PMP media, these values were $5.65 \mathrm{~g} \mathrm{l}^{-1}$ and $4.20 \mathrm{~g} \mathrm{l}^{-1}$ respectively after 15 days of incubation. Lee et al. (2007) obtained $17.8 \mathrm{~g} \mathrm{l}^{-1}, 19.4 \mathrm{~g} \mathrm{l}^{-1}$ and $18.9 \mathrm{~g} \mathrm{l}^{-1}$ cell masses on the media containing glucose, fructose and maltose.
Shivani (2008) had observed the same trend of biomass production using four strains of GL-1, GL-2, GL-3 and GL-4 after 21 days of incubation. Zapata et al. (2012) obtained mycelial biomass $\left(23.49 \pm 0.37 \mathrm{~g} \mathrm{l}^{-1}\right)$; extracellular polysaccharides $\left(2.72 \pm 0.11 \mathrm{~g} \mathrm{l}^{-1}\right)$; intracellular polysaccharides $\left(2.22 \pm 0.06 \mathrm{~g} \mathrm{l}^{-1}\right)$; ganoderic acids production $\left(299.67 \pm 11.63 \mathrm{mg} \mathrm{l}^{-1}\right)$ in G. lucidum on optimal medium composition defined as $\left(\mathrm{g} \mathrm{l}^{-1}\right): 50$ of barley flour, 0.2 of $\mathrm{KH}_{2} \mathrm{PO}_{4}, 0.1$ of $\mathrm{MgSO}_{4} \cdot 7 \mathrm{H}_{2} \mathrm{O}$, and $1 \mathrm{NH}_{4} \mathrm{Cl}$. Fraga et al. (2014) obtained maximum mycelial biomass and exopolysaccharide purity at low peptone level $\left(1.65 \mathrm{~g}^{-1}\right)$ in $G$. lucidum. However, they found maximum exopolysaccharide production at higher amount of peptone $\left(4.80 \mathrm{~g} \mathrm{l}^{-1}\right)$.

Yield evaluation of $\boldsymbol{G}$. lucidum strains: The effect of supplementation of wheat bran revealed that maximum biological efficiency of $10.3 \%$ was obtained at 5 per cent level in GL-1. Moreover, 5 per cent wheat bran supplementation resulted in more fruiting bodies $(72 \mathrm{~g}$ $\mathrm{bag}^{-1}$ ) and mycelia spread was also fast (53 days). Improvement in yield at higher rate of supplementation $(15 \%$ and $20 \%)$ was not significant at 5 per cent level of significance. In case of GL-2, yield data followed the same trend as in case of GL-1 supplementation of wheat bran@ 5 - 15 per cent support better growth and fruiting bodies production than at 20 per cent. Weight of fruiting bodies was highest $\left(91 \mathrm{~g} \mathrm{bag}^{-1}\right)$ in 5 per cent wheat bran supplemented bags as compared to others (Table 2). GL-3 strain was found non-productive on wheat straw as no fruiting body of this strain was

Table 2. Effect of wheat bran supplementation on the yield of GL-1 and GL-2 strains.

\begin{tabular}{|c|c|c|c|c|c|c|c|c|}
\hline \multirow{2}{*}{$\begin{array}{l}\text { Treatments } \\
\text { Supplement } \\
\text { level }(\%)\end{array}$} & \multicolumn{4}{|c|}{ GL-1 strain } & \multicolumn{4}{|c|}{ GL-2 strain } \\
\hline & DSR & $\begin{array}{l}\text { NFB } \\
\mathrm{Bag}^{-1}\end{array}$ & $\begin{array}{c}\mathrm{WFB}(\mathrm{g}) \\
\mathrm{Bag}^{-1}\end{array}$ & BE (\%) & DSR & $\begin{array}{l}\text { NFB } \\
\mathrm{Bag}^{-1}\end{array}$ & $\begin{array}{c}\text { WFB(g) } \\
\mathrm{Bag}^{-1}\end{array}$ & BE $(\%)$ \\
\hline Control & 63 & 3 & 20 & 2.9 & 61 & 4 & 26 & 3.7 \\
\hline 5 & 53 & 8 & 72 & 10.3 & 53 & 6 & 91 & 13.0 \\
\hline 10 & 55 & 5 & 56 & 8.0 & 56 & 2 & 30 & 4.3 \\
\hline 15 & 64 & 4 & 45 & 6.4 & 62 & 6 & 60 & 8.6 \\
\hline 20 & 60 & 3 & 22 & 3.1 & 67 & 3 & 26 & 3.7 \\
\hline $\mathrm{CD}$ at $5 \%$ & & & & 6.78 & & & & 0.77 \\
\hline
\end{tabular}

$\mathrm{DSR}=$ Days for spawn run, NFB= No. of fruiting body, WFB= Weight of fruiting body; Dry wt. of wheat straw/ Bag: $350 \mathrm{~g}$; No. of replicate bags: 15 ; $*$ Strain GL-3 produced no fruiting bodies

Table 3. Polysaccharide, reducing and non reducing sugar contents in G. lucidum strains.

\begin{tabular}{lcccc}
\hline Sample & Strain & $\begin{array}{c}\text { Polysaccharide } \\
\text { yield (\%) }\end{array}$ & $\begin{array}{c}\text { Reducing } \\
\text { sugars (\%) }\end{array}$ & $\begin{array}{c}\text { Non reducing } \\
\text { Sugars (\%) }\end{array}$ \\
\hline \multirow{2}{*}{ Biomass } & GL-1 & 21.40 & 37.92 & 62.08 \\
& GL-2 & 16.00 & 25.45 & 74.55 \\
& GL-3 & 7.67 & 16.61 & 83.39 \\
Crude & GL-1 & 0.86 & 67.72 & 32.28 \\
Extract & GL-2 & 2.87 & 40.25 & 59.75 \\
Fruiting & GL-3 & 2.53 & 22.46 & 77.54 \\
Body & GL-1 & 30.07 & 30.18 & 69.82 \\
\hline
\end{tabular}




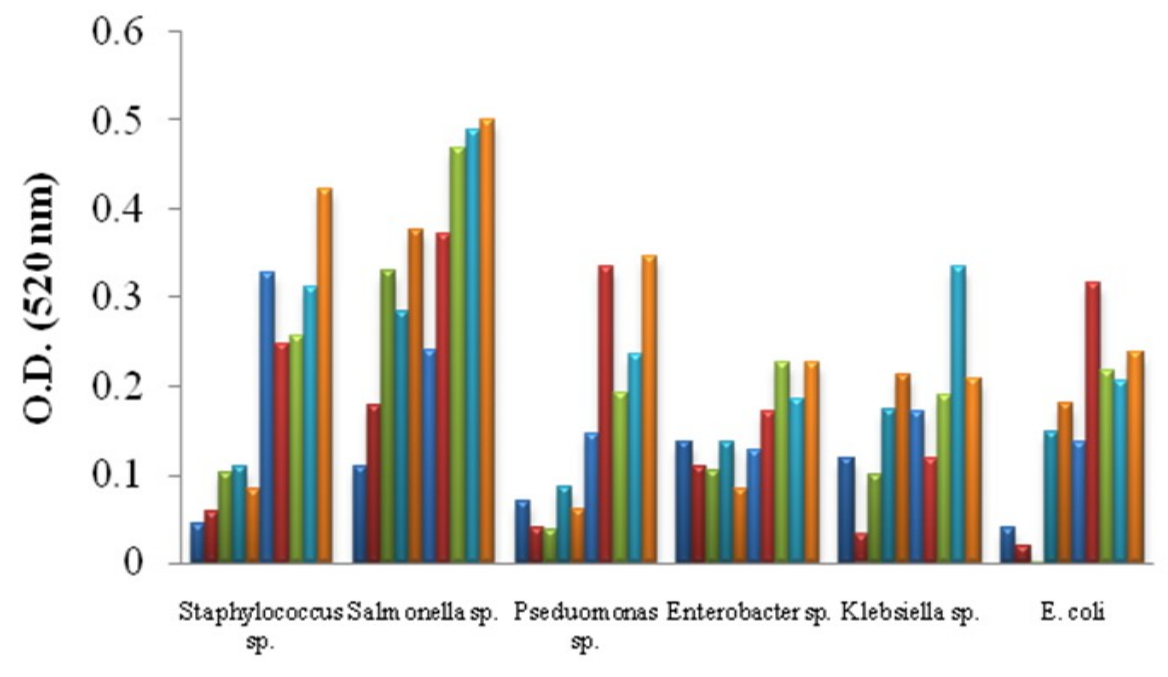

\section{Bacteria}

v Methanolic Biomass GL-1

घethanolic Biomass GL-2

$\square$ Methanolic Biomass GL-3

Methanolic Fruiting body GL-1

Methanolic Fruiting body GL-2

Aqueous biomass GL-1

-Aqueous biomass GL-2

$\square$ Aqueous biomass GL-3

$\square$ Aqueous Fruiting body GL- 1

$\square$ Aqueous Fruiting body GL-2

Fig. 1. Spectro-photometric method to determine quantitative antibacterial activity of extracts of three strains of G. lucidum after 24 hrs.

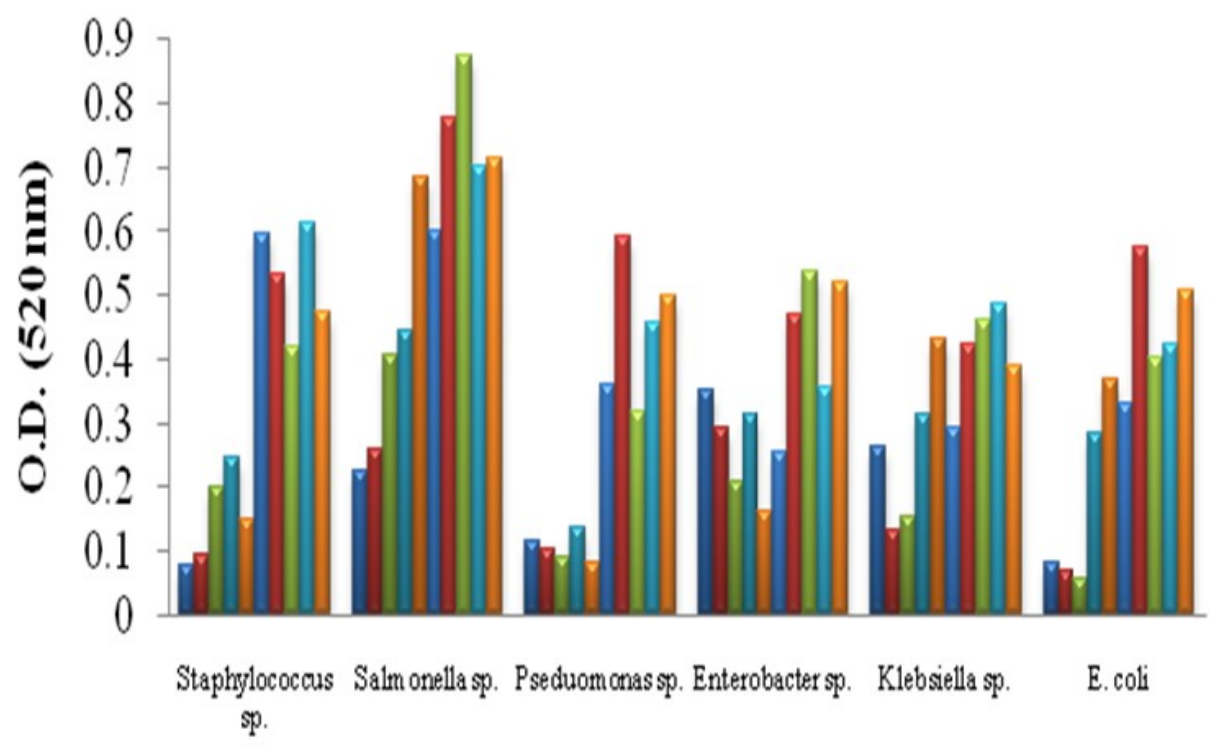

Methano lic Biomass GL-1

"Methano lic Biomass GL-2

Metharolic Biomass GL-3

Methano lic Fruitingbody GL-1

"Methano lic Fruitingbody GL-2

Aqueousbiomass GL-1

$\nabla$ Aqueousbiomass GL-2

$\square$ Aqueousbiomass GL-3

অqueousFruiting body GL-1

\section{Bacteria}

AqueousFruiting body GL-2

Fig. 2. Spectro-photometric method to determine quantitative antibacterial activity of extracts of three strains of G. lucidum after 48 hrs.

obtained.

Chen (1999) reported that rice or wheat bran addition was essential for the successful cultivation of G. lucidum. Addition of rice bran or wheat bran to the substrate takes care of the requirement of thiamine, which is very essential for the mycelial growth and reproduction of G. lucidum. Stamets (2000) reported that over supplementation with rice bran, beyond 15 per cent of the dry mass of the substrate inhibits fruit body development. Mishra and Singh (2006) reported that wheat bran supplemented with 5 per cent rice bran gave significantly higher B.E. $(15-17 \%)$ at 5 per cent level of significance than sawdust as substrate which gave only 5-14 per cent B.E. Shivani (2008) obtained maximum biological efficiency of $G$. lucidum with rice bran $(10.7 \%)$ at 5 per cent as compared to wheat bran $(10.0 \%)$ and further increase in the rate of supplementation resulted in decrease in biological efficiency which corroborate the present findings. Supplementation of both the brans@5-15 per cent supported better growth and fruiting body production than at 20 per cent. The best combinations for high yield $(142.44 \mathrm{~g} / \mathrm{kg})$ and biological efficiency $(18.68 \%)$ of $G$. lucidum were obtained by Azizi et al. (2012) in a combination of poplar sawdust with 5\% malt extract and 10\% wheat bran. The highest mycelia growth rate $(10.6 \mathrm{~mm} /$ day $)$ was obtained in a combination of beech sawdust with $2.5 \%$ malt extract and $10 \%$ wheat bran. Ueitele et al. (2014) concluded that corn cobs have the potential to be used as alternate substrate for Ganoderma mushroom cultivation in Namibia and 
Table 4. Antibacterial activity of the extracts of strains of G. lucidum by filter paper disc method.

\begin{tabular}{|c|c|c|c|c|c|c|c|c|c|c|c|}
\hline \multirow[t]{3}{*}{ Bacteria } & \multirow{3}{*}{$\begin{array}{c}\text { Chloram- } \\
\text { phenicol } \\
\left(10 \mathrm{mg} \mathrm{ml}^{-1}\right)\end{array}$} & \multicolumn{10}{|c|}{ Clear zone diameter $(\mathrm{cm})$} \\
\hline & & \multicolumn{5}{|c|}{ Methanolic extracts } & \multicolumn{4}{|c|}{ Aqueous extracts } & \multirow[b]{2}{*}{$\mathbf{E}$} \\
\hline & & $\mathbf{A}$ & $\mathbf{B}$ & $\mathbf{C}$ & D & $\mathbf{E}$ & $\mathbf{A}$ & $\mathbf{B}$ & $\mathbf{C}$ & $\mathbf{D}$ & \\
\hline Staphylococcus sp. & 3.1 & 2.4 & 2.5 & 2.3 & 2.5 & 2.2 & 1.9 & 1.9 & 2.0 & 1.7 & 1.7 \\
\hline Salmonella sp. & 2.3 & 1.7 & 1.3 & 1.3 & 1.2 & 1.2 & 1.1 & 0.8 & 1.2 & 1.1 & 1.3 \\
\hline Pseudomonas sp. & 2.9 & 1.8 & 1.5 & 1.7 & 1.5 & 1.9 & 1.2 & 1.2 & 0.7 & 0.6 & 0.3 \\
\hline Enterobacter sp. & 2.1 & 2.2 & 2.5 & 2.5 & 1.9 & 1.4 & 1.7 & 1.5 & 1.3 & 1.1 & 1.2 \\
\hline Klebsiella sp. & 1.9 & 1.7 & 1.1 & 1.3 & 1.6 & 1.5 & 1.4 & 1.3 & 1.0 & 1.5 & 1.6 \\
\hline E. coli & 2.5 & 2.0 & 1.5 & 1.4 & 0.9 & 0.9 & 0.5 & 0.7 & 1.2 & 1.0 & 0.5 \\
\hline
\end{tabular}

A: GL-1 Biomass, B: GL-2 Biomass, C: GL-3 Biomass, D: GL-1 Fruiting body, E: GL-2 Fruiting body; Incubation Time: 24 hrs; Incubation Temperature: $37^{\circ} \mathrm{C}$

obtained a higher biological efficiency $(5.32 \%)$ as compared to saw dust $(0.05 \%)$.

Polysaccharides, reducing sugars and non- reducing sugars: The polysaccharides obtained from fruiting bodies and mycelial biomass represents endopolysaccharides and those extracted in the culture filtrate were exopolysaccharides. The maximum yield of polysaccharides was obtained from fruiting bodies (30.06- 63.70\%), followed by mycelial biomass (7.61- $21.32 \%$ ) and culture filtrates (0.86- 2.86\%). Endopolysaccharides were maximum in the fruit bodies of GL-2 strain $(63.70 \%)$ and in the mycelial biomass of GL-1 strain (21.40\%). The exo-polysaccharide production was recorded highest in GL-2 strain $(2.87 \%)$ and minimum in GL-1 strain $(0.86 \%)$ as given in Table 3. Cui et al. (2006) reported $107.34 \mathrm{mg} \mathrm{g}^{-1}, 83.13 \mathrm{mg} \mathrm{g}^{-1}, 105.45 \mathrm{mg} \mathrm{g}^{-1}$ and 98.25 $\mathrm{mg} \mathrm{g}^{-1}$ of total polysaccharides in G. lucidum extract, by conventional vacuum drying; freeze drying, microwave vacuum and conventional vacuum drying on dry weight basis.

Non-reducing sugars were the main fraction in all the cases. Maximum non-reducing sugars were observed in GL-3 strain in biomass and crude extract. However, the non-reducing sugars were found maximum in the fruit body of GL-2 strain. Correspondingly, the amounts of reducing sugars were lesser in extracted polysaccharides from fruiting bodies, mycelial biomass and culture filtrates. Reducing sugars were 29.61 - 30.18 per cent in fruiting body extracted polysaccharides, followed by crude extracts (22.46- 67.72\%) and minimum in biomass polysaccharides (16.61-37.92\%). Lee et al. (2007) reported that endopolysaccharides obtained from $G$. lucidum were containing $76 \%$ glucose, $8 \%$ galactose, $9 \%$ mannose and $7 \%$ xylose, whereas in case of exopolysaccharides, glucose was $81 \%$, galactose $7 \%$, mannose $12 \%$ and xylose was in trace elements. They also isolated a galactose rich extracellular (GLP-2) from submerged culture broth of G. lucidum, which was composed of galactose, mannose, glucose, arabinose and rhamnose in the molar ratios 103: 17: 12: 10:3. Narkprasom et al. (2013) optimized the submerged fermentation conditions for Ganoderma tsugae by using Plackett Burman Design and obtained maximum extracellular polysaccharide content $\left(415 \mathrm{mg} \mathrm{l}^{-1}\right)$ under optimized culture conditions (31.031 $\mathrm{g} \mathrm{l}^{-1}$ maltose,
$14.055 \mathrm{~g} \mathrm{l}^{-1}$ skim milk and an initial $\mathrm{pH}$ of 7.12).

Antibacterial potential of Ganoderma extracts on solid and liquid media: The antibacterial potential of the methanolic and aqueous extracts of G. lucidum strains against six pathogenic bacteria was studied by filter-paper disc and spectrophotometric methods for 24 and 48 hrs. The results of filter paper disc method are presented in Table 4.

Antimicrobial activity of methanolic extracts of biomass and fruit body of all the strains showed effective zone of inhibition as compared to aqueous extracts. The maximum antibacterial activity of methanolic extracts of biomass and fruit body of G. lucidum strains was found against Staphylococcus sp. based on zone of inhibition and minimum against Klebsiella and E. coli. The maximum inhibition zone ranging from 2.2- 2.5 $\mathrm{cm}$ was recorded for Staphylococcus. Aqueous extracts of biomass and fruit body also showed maximum inhibition of growth of Staphylococcus sp. and minimum of Pseudomonas sp. The maximum inhibition zone was ranging from $1.8-2.0 \mathrm{~cm}$ for Staphylococcus.

In case of spectrophotometric method, increase in incubation period ( 24 to $48 \mathrm{hrs}$ ) resulted in decrease in antibacterial potential as manifested by increase of optical density (OD) Methanolic extracts were again found to be more effective against pathogenic bacteria as compared to aqueous extracts. These extracts were inhibitory to all the bacterial spp. except Salmonella sp. which was least inhibited by these extracts. Overall these extracts were having variable responses towards pathogenic bacteria, and these variations were also observed to different strains of G. lucidum (Figs. 1 and 2). The results of the present study are somewhat corroborated by the findings of Kamble et al. (2011) who reported that methanol, acetone, chloroform and aqueous extracts of $G$. lucidum biomass to be more effective against Staphylococcus aureus, Bacillus subtilis, and Corynebacterium diphtheriae, whereas these extracts were least inhibitory against E. coli, Proteus mirabilis, K. pneumoniae, Salmonella typhii and Pseudomonas P18. Bhosle et al. (2010) regarded G. lucidum as a broad spectrum antibiotic which were highly effective against both Gram positive as well as Gram negative bacteria. Singh et al. (2014) reported acetone and methanolic extract of G. lucidum fruiting body possessed 
strong antimicrobial activity and considered as antimicrobial agent which can be used in the development of new drug for the different bacterial and fungal pathogenesis in humans.

\section{Conclusion}

Three indigenous strains of Ganoderma lucidum were screened for biomass, polysaccharide production and biological efficiency during cultivation indicated that strain GL-3 to be the most potential strain producing for maximum biomass production in liquid culture, whereas strain GL-1 and GL-2 can be exploited for cultivation of this fungus. The extracted polysaccharides showed potential antimicrobial activity against bacterial pathogens. Thus, bioactive components from G. lucidum strains are promising antimicrobial agents that can be harnessed as potent antimicrobial toxicant.

\section{REFERENCES}

Azizi, M., Tavana, M., Farsi, M. and Oroojalian, F. (2012). Yield performance of lingzhi or reishi medicinal mushroom, Ganoderma lucidum (W.Curt.:Fr.) P. Karst. (Higher Basidiomycetes), using different waste materials as substrates. International Journal of Medicinal Mushrooms, 14: 521-527.

Bhosle, S.R., Bapat, G., Vaidya, J.G. and Garad, S.A. (2010). Antimicrobial activity of terpenoid extracts from Ganoderma samples. International Journal of Pharmacy and Life Sciences, 1: 234-240.

Chang, S.T. and Miles, P.G. (2004). Mushrooms: Cultivation, Nutritional Value, Medicinal Effect, and Environmental Impact, $2^{\text {nd }}$ edition. CRC Press, Boca Raton, FL.

Chen, A.W. (1999). Cultivation of the medicinal mushroom Ganoderma lucidum (Curt: Fr) P Karst (Reishi) in North America. International Journal of Medicinal Mushrooms, 1: 263-82.

Cui, Z.W., Xu, S.Y., Sun, D.W. and Chen, W. (2006). Dehydration of concentrated Ganoderma lucidum extraction by combined microwave-vaccum and conventional vaccum drying. Drying Technology, 24: 595-599.

Dubois, M., Gilles, K.A., Hamilton, J.K., Robers, P.A. and Smith, F. (1956). Colorimetric method for determination of sugars and related substrates. Analytical Chemistry, 28: 350-356.

Fraga, I., Coutinho, J., Bezerra, R.M., Dias, A.A., Marques, G. and Nunes, F.M. (2014). Influence of culture medium growth variables on Ganoderma lucidum exopolysaccharides structural features. Carbohydrate Polymers, 111: 936-946.

Gao, J.J., Min, B.S., Ahn, E.M., Nakamura, N., Lee, H.K. and Hattori, M. (2002). New triterpene aldehydes, lucialdehydes A-C, from Ganoderma lucidum and their cytotoxicity against murine and human tumor cells. Chemical and Pharmaceutical Bulletin (Tokyo), 50: 837-840.

Gao, Y., Tank, W., Gao, H., Tan, J. and Zhou, S. (2004). Chemopreventive and tumoricidal properties of Lingzhi mushroom Ganoderma lucidum (W. Curt.:Fr.) Lloyd (Aphyllophorophoromycetideae). I. Preclinical and clinical studies (review). International Journal of Medicinal Mushrooms, 6: 95-106.

Kalsi, M. (2002). Cultivation and anti-oxidative effects of Pleurotus spp. MSc. Thesis, Punjab Agricultural University, Ludhiana, India.

Kamble, R., Venkata, S. and Gupta, A.M. (2011). Antimicrobial activity of Ganoderma lucidum mycelium. Journal of Pure and Applied Microbiology, 5(2): 983-986.

Kim, S.W., Hwang, H.J., Park, J.P., Cho, Y.J., Song, C.H. and Yun, J.W. (2002). Mycelial growth and exo-biopolymer production by submerged culture of various edible mushrooms under different media. Letters in Applied Microbiology, 34: 56-61.

Lee, I.K., Kim, Y.S., Jang, Y.W., Jung, J.Y. and Yun, B.S. (2007). New antioxidant polyphenols from the medicinal mushroom Inonotus obliquus. Bioorganic and Medical Chemistry Letters, 17: 6678-6681.

Lin, Z.B. and Zhang, H.N. (2004). Anti-tumor and immunoregulatory activities of Ganoderma lucidum and its possible mechanisms. Acta Pharmacologica Sinica, 25: 1387- 1395.

Miller, G.L. (1959). Use of dinitrosalicylic acid reagent for determination of reducing sugars. Annals of Chemistry, 31: 426-428.

Mishra, K.K. and Singh, R.P. (2006). Exploitation of indigenous Ganoderma lucidum for yield on different substrates. Journal of Mycology and Plant Pathology, 36: 130-133.

Narkprasom, N., Guo, J.H., Huang T.C. and Guu, Y.K. (2013). Combination of statistical techniques for submerged fermentation for extracellular polysaccharide and biomass of Ganoderma tsugae. American Journal of Biostatistics, 3: 38-46.

Ofodile, L.N., Uma, N.U., Kokubum, T., Grayer, R.J., Ogundipe, O.T. and Simnonds, M.S.J. (2005). Antimicrobial activity of some Ganoderma species from Nigeria. Phytotherapia Research, 19: 210-213.

Shivani (2008). Optimization of conditions for submerged and solid state fermentation for mycelial biomass, exobiopolymers and sporophore production of Ganoderma lucidum. M.Sc. Thesis, Punjab Agricultural University, Ludhiana, India.

Singh, J., Gupta, S., Malviya, S. and Ahrwar, B. (2014). In-vitro evaluation of antimicrobial activity of Ganoderma lucidum. International Journal of Advanced Research, 2: 460-466.

Stamets, P. (2000). Growing Gourmet and Medicinal Mushrooms. $3^{\text {rd }}$ ed CA: Ten Speed Press, Berkeley, California, pp 259-276.

Ueitele, I.S.E., Kadhila-Muandingi, N.P. and Matundu, N. (2014). Evaluating the production of Ganoderma mushroom on corn cobs. African Journal of Biotechnology, 13: 2215-2219.

Xu, Z., Chen, X., Zhong, Z., Chen, L. and Wang, Y. (2011). Ganoderma lucidum polysaccharides: immunomodulation and potential anti-Tumor activities. American Journal of Chinese Medicine, 39: 15-27.

Yap, A.T. and Ng, M.L. (2001). An improved method for the isolation of lentinan from the edible and medicinal shiitake mushroom, Lentinus edodes (Berk) Sing (Agaricomycetideae). International Journal of Medicinal Mushrooms, 3: 6-19.

Zapata, P., Rojas, D. and Atehortúa, L. (2012). Production of biomass, polysaccharides, and ganoderic acid using non -conventional carbon sources under submerged culture of the Lingzhi or Reishi medicinal mushroom, Ganoderma lucidum (W.Curt.:Fr.) P. Karst. (higher Basidiomycetes). International Journal of Medicinal Mushrooms 14: 197-203.

Zhu, X.L., Chen, A.F. and Lin, Z.B. (2007). Ganoderma lucidum polysaccharides enhance the function of immunological effector cells in immunosuppressed mice. Journal of Ethnopharmacology, 111: 219-226.

Zjawiony, J.K. (2004). Biologically active compounds from Aphyllophorales (polypore) fungi. Journal of Natural Products, 67: 300-310. 